\title{
Correction to: Effectiveness of aripiprazole once-monthly in schizophrenia patients pretreated with oral aripiprazole: a 6- month, real-life non-interventional study
}

Daniel Schöttle ${ }^{1 *}$, Wolfgang Janetzky ${ }^{2}$, Daniel Luedecke ${ }^{1}$, Elmar Beck ${ }^{3}$, Christoph U. Correll ${ }^{4,5,6}$ and Klaus Wiedemann ${ }^{1}$

Correction to: BMC Psychiatry (2018) 18:365 https://doi.org/10.1186/s12888-018-1946-x

Following publication of the original article [1], the authors notified us that the color labelling in Fig. 4 was incorrect.

The corrected Fig. 4 is presented below.

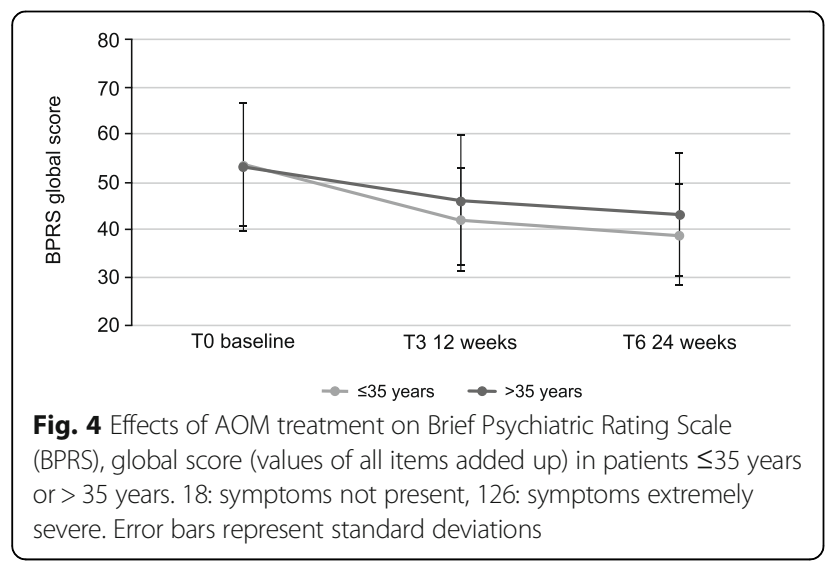

\begin{abstract}
Author details
${ }^{1}$ Klinik für Psychiatrie und Psychotherapie, Zentrum für Psychosoziale, Medizin, Universitätsklinikum Hamburg-Eppendorf, Martinistrasse 52, 20, ,246 Hamburg, Germany. ${ }^{2}$ Lundbeck GmbH, Ericusspitze 2, 20, 457 Hamburg, Germany. ${ }^{3}$ ANFOMED GmbH, Röttenbacher Str. 17, 91,096, Möhrendorf, Germany. ${ }^{4}$ Department of Psychiatry, The Zucker Hillside Hospital, Northwell Health, 75-59 263rd St, Glen Oaks, NY 11004, USA. ${ }^{5}$ Department of Psychiatry and Molecular Medicine, Hofstra Northwell School of Medicine, 500 Hofstra Blvd, Hempstead, NY 11549, USA. ${ }^{6}$ Department of Child and Adolescent Psychiatry, Charité Universitätsmedizin, Augustenburger Platz 1 (Mittelallee 5A), 13, ,353 Berlin, Germany.
\end{abstract}

Received: 29 November 2018 Accepted: 29 November 2018 Published online: 14 December 2018

Reference

1. Schöttle, et al. Effectiveness of aripiprazole once-monthly in schizophrenia patients pretreated with oral aripiprazole: a 6-month, real-life non-interventional study (2018). 2018;18:365. https://doi.org/10.1186/s12888-018-1946-x.

\footnotetext{
* Correspondence: d.schoettle@uke.de

${ }^{1}$ Klinik für Psychiatrie und Psychotherapie, Zentrum für Psychosoziale, Medizin, Universitätsklinikum Hamburg-Eppendorf, Martinistrasse 52, 20, ,246 Hamburg, Germany

Full list of author information is available at the end of the article
}

(c) The Author(s). 2018 Open Access This article is distributed under the terms of the Creative Commons Attribution 4.0 International License (http://creativecommons.org/licenses/by/4.0/), which permits unrestricted use, distribution, and reproduction in any medium, provided you give appropriate credit to the original author(s) and the source, provide a link to the Creative Commons license, and indicate if changes were made. The Creative Commons Public Domain Dedication waiver (http://creativecommons.org/publicdomain/zero/1.0/) applies to the data made available in this article, unless otherwise stated. 